\title{
PENILAIAN KINERJA AUDITOR BERBASIS WEB DI KANTOR AKUNTAN PUBLIK (KAP) PEDDY HF.DASUKI
}

\author{
Salman Khemaludin Yoesoef ${ }^{1}$, Asti Herliana ${ }^{2}$ \\ 1 Universitas Adhirajasa Reswara Sanjaya \\ e-mail: salman.yoesoef99@gmail.com \\ ${ }^{2}$ Universitas Adhirajasa Reswara Sanjaya \\ e-mail: asti@ars.ac.id
}

\begin{abstract}
Abstrak
Dalam ketentuan standar kinerja profesi auditor, kualitas kinerja dari seorang auditor beserta hasil audit harus dipertahankan sesuai aturan yang ada. Salah satu perusahaan atau organisasi yang menggunakan kinerja auditor dan harus mempertahankan kualitas pelayanannya adalah Kantor Akuntan Publik (KAP) PEDDY HF.DASUKI. Tingginya peranan auditor untuk objek penelitian kali ini dikarenakan jenis layanan yang diberikan adalah berupa layanan atestasi dan non atestasi yang merupakan ranah pekerjaan dari seorang auditor. Permasalahan yang diangkat pada penelitian di Kantor Akuntan Publik (KAP) PEDDY HF.DASUKI adalah belum adanya sebuah sistem penilaian hasil unjuk kerja auditor yang menyebabkan potensi auditor tidak dapat dinilai secara lebih objektif. Adanya permasalahan ini berimbas juga pada menurunnya motivasi kerja dari para auditor yang ada karena manajer tidak dapat memberikan penghargaan terhadap kinerja auditor dengan penilaian yang objektif. Untuk mengatasi permasalahan pada objek penelitian kali ini, maka diusulkan sebuah sistem aplikasi penunjang keputusan yang bertujuan untuk membantu manajer dalam memberikan penilaian berdasarkan prestasi kerja dari para auditor, sekaligus dapat memberikan jenis penghargaan yang sesuai dengan prestasi kerja yang telah diberikan secara lebih objektif. Metode yang digunakan untuk mendukung sistem penunjang keputusan yang digunanakan pada penelitian kali ini adalah metode Simple Additive Weighting (SAW) yang telah terbukti dapat memberikan hasil yang baik pada penelitian sejenis terdahulu. Hasil dari penelitian kali ini menunjukkan bahwa dengan adanya sistem penunjang keputusan penilaian kinerja auditor dapat memberikan hasil penilaian yang lebih objektif terhadap hasil prestasi kerja dari para auditor dengan menitik beratkan penilaian pada 4 kriteria yakni hasil kerja, jobdesk, komunikasi dan kasus.
\end{abstract}

Kata Kunci: Auditor, Penilaian, Kinerja, Sistem Penunjang Keputusan, Metode SAW

\begin{abstract}
In the provisions of the auditor's professional performance standards, the quality of the performance of an auditor along with the audit results must be maintained in accordance with existing rules. One company or organization that uses auditor performance and must maintain the quality of its services is the Public Accounting Firm (KAP) PEDDY HF.DASUKI. The high role of auditors for the object of this research is because the types of services provided are in the form of attestation and non-attestation services which are the realm of work of an auditor. The problem raised in the research at the Public Accounting Firm (KAP) PEDDY HF.DASUKI is that there is no system for assessing the results of auditor performance, which causes potential auditors to not be assessed more objectively. The existence of this problem also has an impact on the decrease in work motivation of the existing auditors because managers cannot reward auditor performance with an objective assessment. To overcome the problems in the object of
\end{abstract}


this research, a decision support application system is proposed that aims to assist managers in providing an assessment based on the work performance of the auditors, as well as being able to provide the type of award that is in accordance with the work performance that has been given more objectively. The method used to support the decision support system used in this study is the Simple Additive Weighting (SAW) method which has been proven to provide good results in previous similar studies. The results of this study indicate that the existence of a decision support system for assessing the performance of auditors can provide a more objective assessment of the work performance of the auditors by emphasizing the assessment on 4 criteria, namely work results, job desk, communication and cases.

\section{Keywords: Auditor, Assessment, Performance, Decision Support System, SAW Method}

\section{Pendahuluan}

Auditor merupakan salah satu profesi yang memiliki tingkat persaingan yang ketat dan permintaan yang juga meningkat setiap tahunnya. Hal ini senada dengan apa yang disampaikan oleh Ketua Komite Profesi Akuntan Publik Firmansyah N. Nazaroedin, Ak, M.SC pada kegiatan webinar tangal 16 Desember 2020 secara daring (Komite Profesi Akuntan Publik, 2020). Auditor sendiri dapat diartikan sebagai orang yang memiliki peranan penting dalam aktivitas audit. Sebagaimana telah dipahami oleh khalayak ramai, kegiatan audit (auditor) dilakukan oleh seseorang yang berprofesi sebagai akuntan publik. Seorang akuntan publik yang mempunyai banyak pengetahuan tentang kekeliruan akan lebih ahli dalam melaksanakan tugasnya terutama yang berhubungan dengan pengungkapan kekeliruan dalam (Muhammad, 2013).

Seorang akuntan publik (auditor) dikatakan ahli jika memiliki beberapa kemampuan seperti independensi, integritas dan kompetensi. Hal ini diperlukan karena seorang auditor bertugas untuk mengevaluasi kinerja baik dalam sebuah perusahaan ataupun perseorangan untuk mengetahui adanya kemungkinan terjadi kesalahan (penyimpangan), baik yang bersifat kepatuhan, inefisensi, kecurangan,dan lain sebagainya yang memiliki kaitan dan relevansi dengan laporan keuangan. Dengan istilah lain, fungsi dari audit dirancang sedemikian ruap agar dapat melakukan pengawasan terhadap hal yang berkaitan dengan keuangan (jaminan keamanan asset perusahaan) serta menghasilkan informasi akuntansi yang tepat, sesuai juga relevan (Erfiansyah \& Kurnia, 2018).

Salah satu perusahaan atau organisasi yang menggunakan kinerja auditor adalah Kantor Akuntan Publik (KAP)
PEDDY HF.DASUKI. Permasalahan yang dihadapi oleh manager pada Kantor Akuntan Publik (KAP). PEDDY HF.DASUKI adalah belum adanya sistem penunjang keputusan untuk menentukan penilaian kinerja dari para auditor yang berimbas pada permasalahan-permasalahan lain seperti menurunnya kualitas kerja dari para auditor karena sistem reward yang diberikan dianggap kurang objektif. Maka untuk mengatasi permasalahan tersebut, diusulkan sebuah sistem penunjang keputusan berbasis web dengan menggunakan metode Simple Additive Weighting (SAW) untuk metode penilaiannya.

Metode SAW dipilih karena metode ini mampu untuk memberikan penilaian dengan lebih akurat terhadap kriteria yang ada pada KAP PEDDY HF.DASUKI yakni hasil kerja, jobdesk, komunikasi dan kasus. Keunggulan dari SAW ini didasarkan pada nilai kriteria dan bobot preferensi yang sudah ada sebelumnya (Anto et al., 2015). Penelitian mengenai metode SAW sebelumnya telah digunkan oleh (Putra, Aryanti, \& Hartati, 2018) dalam menentukan guru terbaik di SMK Global Surya. Kriteria yang digunakan ada 6 (enam) yaitu, absensi, indeks prestasi individual, indeks prestasi siswa yang dibina, penilaian kuisioner, interaksi sosial, pendidikan terakhir. hasil perhitungan bobot dengan menggunakan metode SAW, sehingga didapat nilai terbesar ada pada A10 yang terpilih sebagai alternatif terbaik dan dari alternatif tertinggi maka guru yang bersangkutan dinyatakan memiliki kinerja yang memuaskan dalam proses mengajar kepada siswa. Penelitian yang lain dari (Rachman, 2018) mengenai metode SAW yang digunakan untuk penilaian kinerja karyawan dengan 11 kriteria yaitu inisiatif, kepatuhan, pengetahuan dan keterampilan, komunikasi dan kerjasama, kepemimpinan, 
tanggung jawab, hasil pekerjaan, disiplin, pemecahan masalah, loyalitas dan kehadiran. Hasil dari penelitian ini adalah hasil penilaian karyawan sangat akurat dari pada yang manual dan juga memudahkan kepala bagian dalam membuat laporan hasil kinerja karyawan.

Penelitian lain dilakukan oleh (Hidayati et al., 2018) yang mengkombinasikan metode SAW dengan metode AHP. Kriteria yang digunakan pada penelitian ini adalah KPI, Weekly Report, dan nilai preferensi. Hasil dari penelitian ini adalah, meski pada sebuah eksekusi terdapat nilai yang sama diantara beberapa karyawan namun hasil penilaian tetap dapat dibandingkan karena adanya jangkauan nilai yang telah tersimpan pada sistem. Sedangkan penelitian yang telah membuktikan bawah metode SAW dapat bekerja optimal dengan platform web telah dibuktikan pada penelitan (Darmastuti, 2013) dimana objek yang diambil pada penelitian ini adalah pencari kerja terbaik pada sebuah lowongan pekerjaan. Penelitian lain yang juga membuktikan bahwa metode SAW dapat memberikan hasil yang baik dengan menggunakan platform web adalah penelitian yang dilakukan oleh (Fauzan, Indrasary, \& Muthia, 2017) dimana objek penelitian yang dipilih adalah Beasiswa Bidik Misi di POLIBAN. Selain kedua penelitian yang telah disebutkan, penelitian lainnya yang dijadikan acuan pemilihan platform web sebagai usulan penelitian kali ini adalah penelitian yang dilakuan oleh (Rini, Dedi, \& Riyanti, 2015) dimana objek penelitiannya adalah pemilihan dosen terbaik di STMIK Global Tangerang.

\section{Metode Penelitian}

Proses pembangunan penilaian kinerja auditor berbasis web membutuhkan beberapa tahapan yang perlu dilakukan untuk dapat menghasilkan suatu sistem yang berguna bagi manajer Kantor Akuntan Publik Peddy HF.Dasuki.

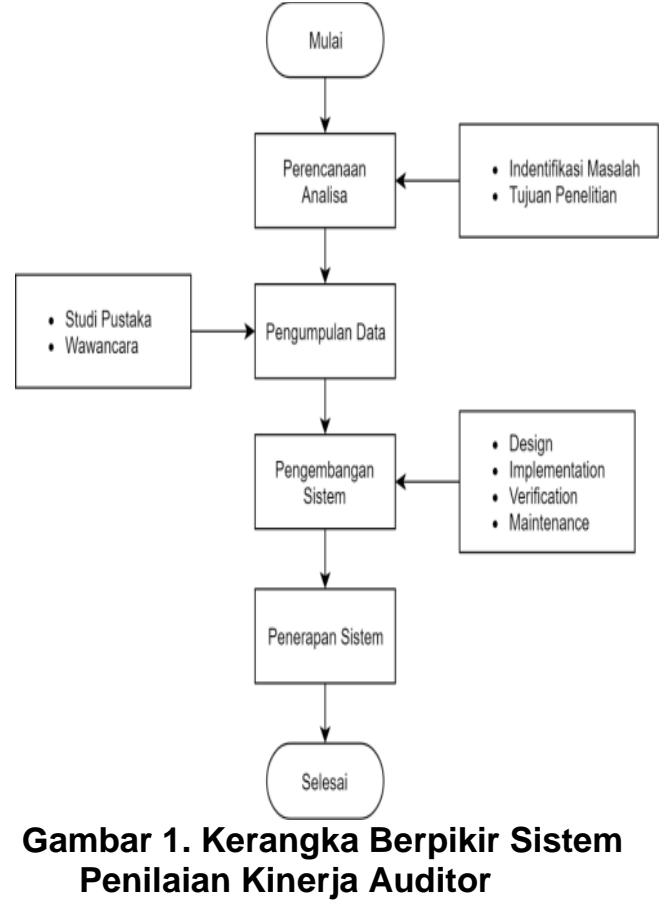

a. Tahapan Perencanaan Analisa

Tahap ini merupakan tahapan awal dalam pembangunan suatu sistem yang dapat menentukan tujuan dari pembangunan sistem itu sendiri, Dalam tahap ini terdapat hal-hal yang perlu dilakukan dengan tujuan agar proses penelitian dapat berlangsung secara efektif dan efisien. kegiatan-kegiatan dalam tahap perencanaan analisa berupa identifikasi masalah, penentuan tujuan penelitian, penentuan kebutuhan sumber data, dan penentuan kebutuhan sistem.

b. Tahap Pengumpulan Data

Pengumpulan data dilakukan dengan cara menggali informasi secara langsung melalui wawancara bersama narasumber. Narasumber yang dimaksud dalam penelitian ini yaitu manajer Kantor Akuntan Publik Peddy HF.Dasuki, pengumpulan data juga dilakukan dengan cara mencari dokumen-dokumen yang akan menjadi bahan acuan dalam penelitian. Pada dasarnya tahapan ini bukan hanya sekedar kegiatan pengumpulan data, tetapi juga merupakan kegiatan pengelompokan data yang sudah tersedia sesuai dengan kategori tertentu sehingga dapat memudahkan pada proses selanjutnya.

c. Tahap Pengembangan Sistem

Pengembangan sistem merupakan tahap penyusunan sistem yang baru untuk menggantikan atau memperbaiki sistem yang sedang berjalan. Sistem yang baru 
diharapkan dapat meningkatkan efisiensi dan kinerja para penggunanya. Pada tahapan ini terdapat siklus hidup yang menjadi standar proses dalam pengembangan suatu sistem yaitu design, implementation, verification, dan maintenance.

d. Tahap Penerapan Sistem

Penerapan sistem merupakan proses untuk menempatkan sistem baru agar dapat digunakan. Selain itu, penerapan sistem juga berfungsi sebagai proses untuk memastikan aplikasi mencapai tujuan yang diinginkan. Tahap ini dilakukan bersama manajer dan dikomunikasikan, sehingga dapat menjadi usulan dalam pengembangan aplikasi selanjutnya.

\section{Hasil dan Pembahasan}

Pada bagian ini, dijelaskan hasil penelitian dan memberikan pembahasan yang komprehensif. Hasil dapat disajikan dalam angka, grafik, tabel, dan lain-lain yang membuat pembaca memahami dengan mudah. Pada bagian ini ditekankan nilai baru dari setiap penelitian yang memuat inovasi, serta implikasinya. Pembahasan dapat dibuat dalam beberapa sub-bab.

\subsection{Use Case Diagram}

\section{a. Admin}

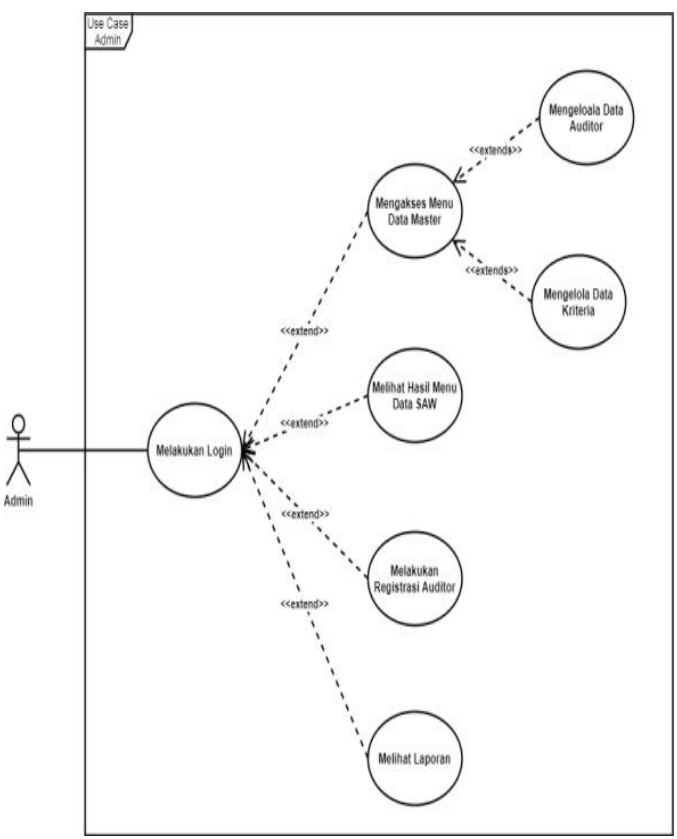

Gambar 2. Usecase Admin

Pada sistem, admin dapat melakukan proses registrasi auditor, mengelola data master, melihat hasi menu data SAW dan melihat laporan. Pada menu kelola data master terdapat sub menu kelola data auditor dan kelola data kriteria.

b. Manajer

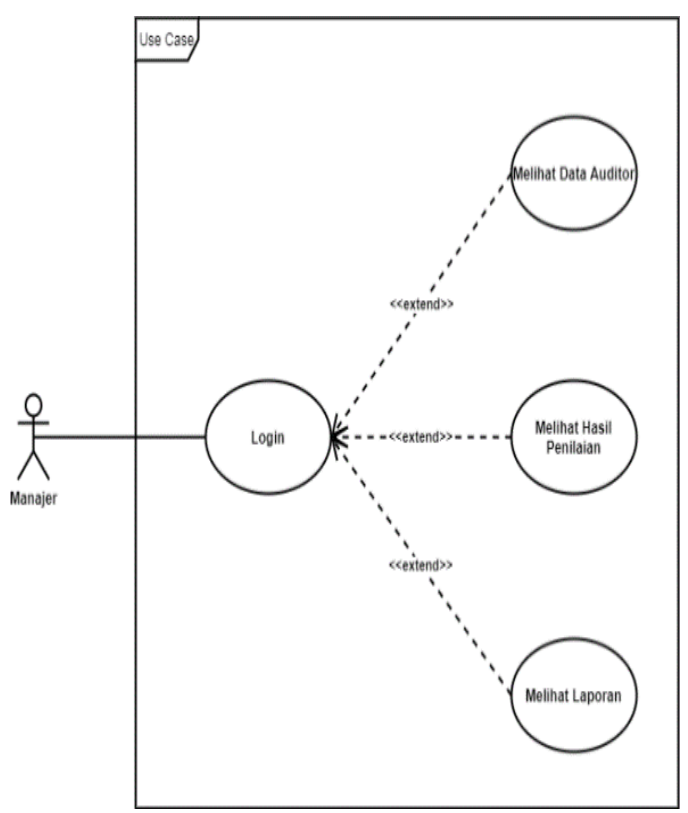

Gambar 3. Usecase Manajer

Pada usecase manajer terdapat beberapa hal yang dapat dilakukan yakni melihat data auditor, melihat hasil penilaian dan juga melihat hasil laporan.

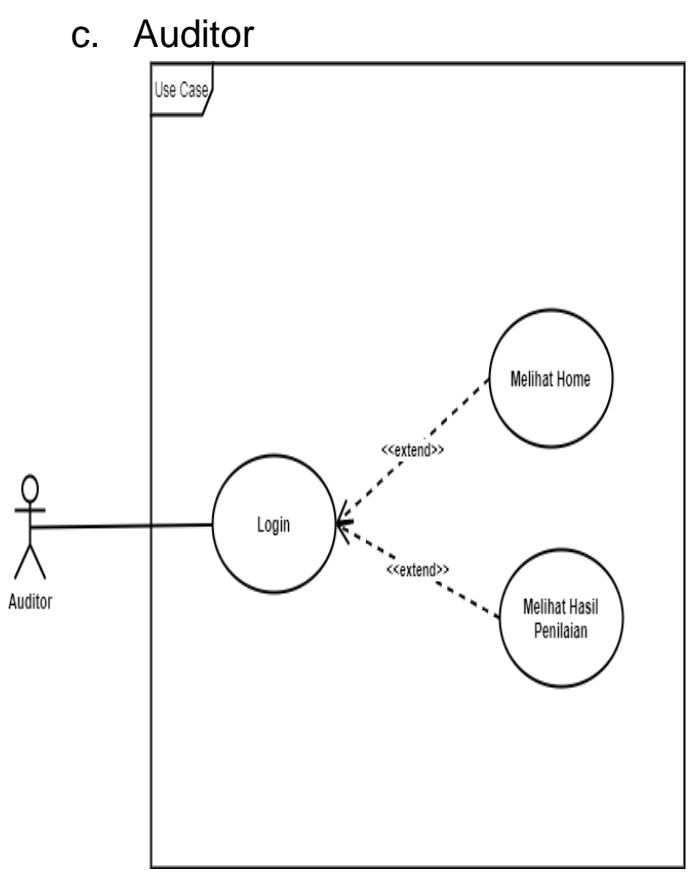

Gambar 4. Usecase Auditor 
Pada sistem auditor terdapat beberapa hal yang dilakukan yakni melihat tampilan home dan juga melihat hasil penilaian.

\subsection{Activity Diagram}

\section{a. Activity Diagram Login}

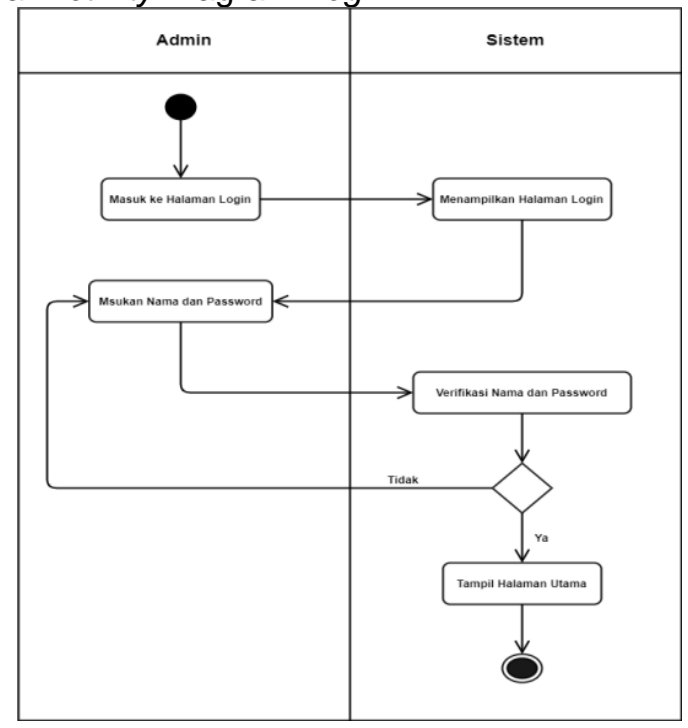

Gambar 5. Activity Diagram Login

Pada diagram aktivitas proses login, ditentukan jenis akses yang akan diproses selanjutnya oleh sistem. Jenis akses yang ada adalah admin, manajer dan auditor.

\section{b. Activity Diagram Data SAW}

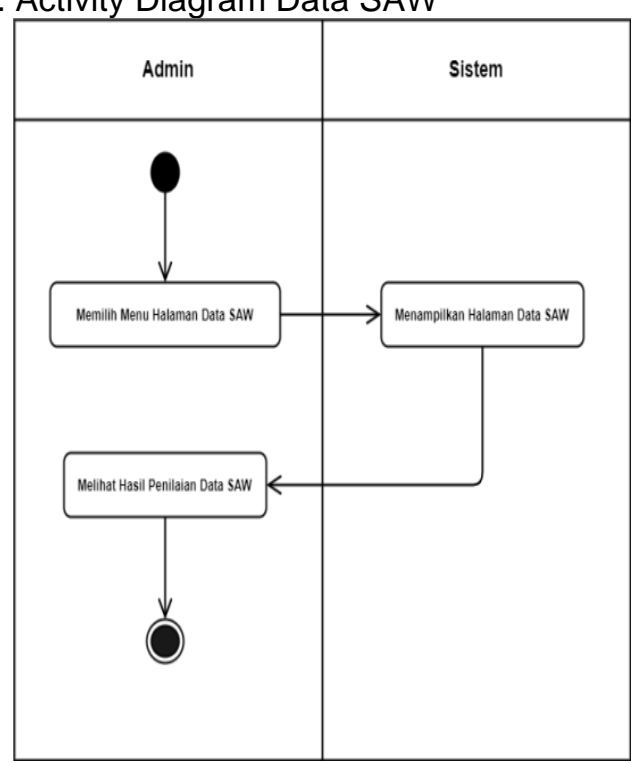

Gambar 6. Activity Diagram Data SAW

Kegiatan yang dilakukan pada proses diagram data SAW adalah merupakan kegiatan inti dari sistem ini yakni proses penilaian terhadap auditor dengan beberapa kriteria yang ada.

\subsection{Sequence Diagram}

a. Sequence Diagram Login

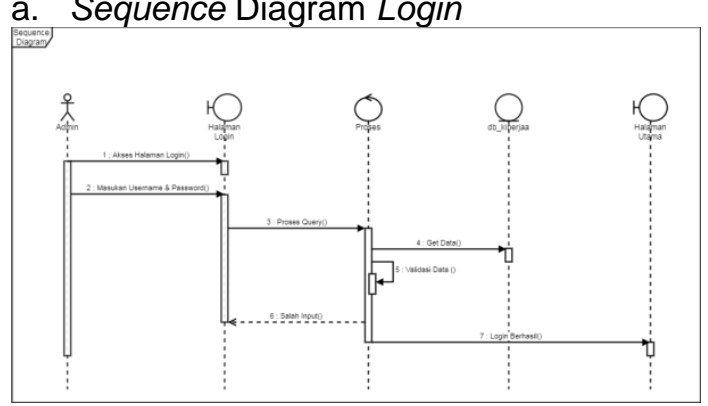

Gambar 7. Sequence Diagram Login

\subsection{ERD}

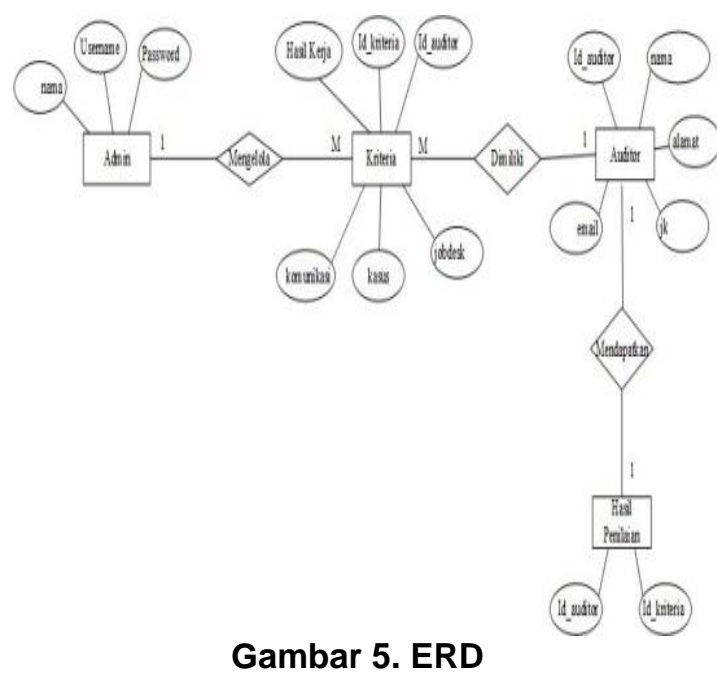

Diagram ERD yang terbentuk pada penelitian kali ini menmpilkan 4 entitas kuat yakni Admin, Kriteria, Auditor, dan Hasil Penilaian.

\subsection{User Interface}

a. Halaman Login

KAP PEDDY HF.DASUKI

\section{Masuk}

Gambar 8. Halaman Login 
b. Halaman Data Auditor
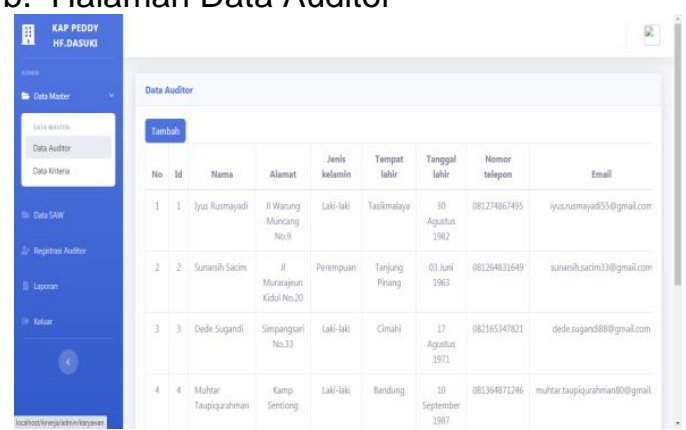

Gambar 9. Halaman Data Auditor

c. Halaman Hasil Penilaian

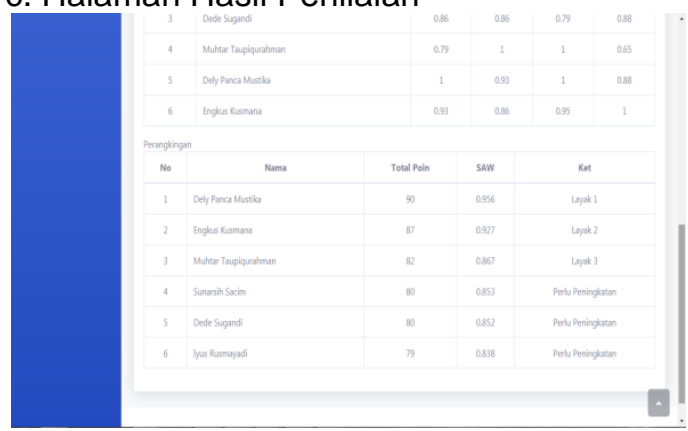

Gambar 10. Halaman Hasil Penilaian

d. Halaman Laporan

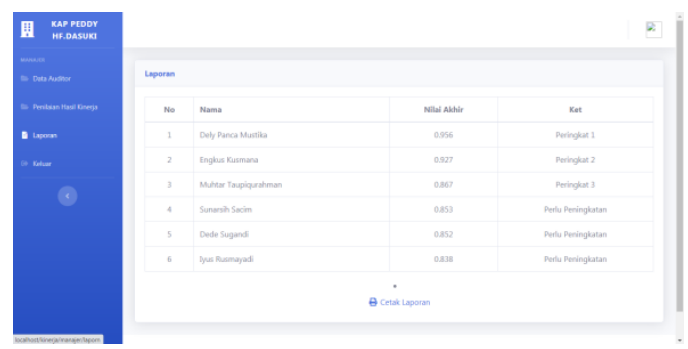

Gambar 11. Halaman Laporan

\subsection{Pengujian Sistem}

Pengujian sistem merupakan bagian yang cukup penting dalam pembuatan aplikasi. Pengujian dilakukan untuk mengetahui kualitas dan kelemahan dari aplikasi. Pengujian aplikasi ini menggunakan suatu metode pengujian Black Box. Pengujian Black Box digunakan untuk menguji semua fungsi-fungsi yang terdapat dalam aplikasi.

Tabel 1. Testing Halaman Admin

\begin{tabular}{|c|l|l|c|c|}
\hline No & $\begin{array}{l}\text { Skenario } \\
\text { Pengujian }\end{array}$ & $\begin{array}{l}\text { Hasil yang } \\
\text { diharapkan }\end{array}$ & $\begin{array}{c}\text { Hasil } \\
\text { Pengujian }\end{array}$ & Kesimpulan \\
\hline 1 & $\begin{array}{l}\text { Memilih } \\
\text { menu } \\
\text { Data } \\
\text { Master }\end{array}$ & $\begin{array}{l}\text { Menampilkan } \\
\text { Submenu } \\
\text { Data Auditor } \\
\text { dan } \\
\text { Submenu }\end{array}$ & $\begin{array}{c}\text { Sesuai } \\
\text { Harapan }\end{array}$ & Valid \\
& & \\
\hline
\end{tabular}

\begin{tabular}{|c|c|c|c|c|}
\hline & & Data Kriteria & & \\
\hline 2 & $\begin{array}{l}\text { Memilih } \\
\text { Submenu } \\
\text { Data } \\
\text { Auditor }\end{array}$ & $\begin{array}{l}\text { Ketika } \\
\text { memasukan } \\
\text { data auditor } \\
\text { lalu di } \\
\text { simpan, } \\
\text { maka akan } \\
\text { menampilkan } \\
\text { data-data } \\
\text { auditor di } \\
\text { submenu } \\
\text { data auditor }\end{array}$ & $\begin{array}{l}\text { Sesuai } \\
\text { Harapan }\end{array}$ & Valid \\
\hline 3 & $\begin{array}{l}\text { Memilih } \\
\text { Submenu } \\
\text { Data } \\
\text { Kriteria }\end{array}$ & $\begin{array}{l}\text { Ketika sudah } \\
\text { mempunayai } \\
\text { setiap data } \\
\text { auditor maka } \\
\text { proses } \\
\text { penilaian } \\
\text { dapat di } \\
\text { lakukan } \\
\text { dengan cara } \\
\text { memasukan } \\
\text { id auditor } \\
\text { yang sudah } \\
\text { ada di } \\
\text { Submenu } \\
\text { Data Kriteria } \\
\text { untuk } \\
\text { dilakukan } \\
\text { penilaian }\end{array}$ & $\begin{array}{l}\text { Sesuai } \\
\text { Harapan }\end{array}$ & Valid \\
\hline 4 & $\begin{array}{l}\text { Memilih } \\
\text { menu } \\
\text { Data SAW }\end{array}$ & $\begin{array}{l}\text { Ketika sudah } \\
\text { memasukan } \\
\text { penilaian } \\
\text { maka proses } \\
\text { penilaian } \\
\text { akan di } \\
\text { proses di } \\
\text { menu Data } \\
\text { SAW yang } \\
\text { akan } \\
\text { menampilkan } \\
\text { hasil dari } \\
\text { metode SAW }\end{array}$ & $\begin{array}{l}\text { Sesuai } \\
\text { Harapan }\end{array}$ & Valid \\
\hline 5 & $\begin{array}{l}\text { Memilih } \\
\text { menu } \\
\text { Registrasi } \\
\text { Auditor }\end{array}$ & $\begin{array}{l}\text { Ketika } \\
\text { memasukan } \\
\text { semua data } \\
\text { yang } \\
\text { dibutuhkan } \\
\text { untuk } \\
\text { registrasi, } \\
\text { maka } \\
\text { registrasi } \\
\text { berhasil } \\
\text { dilakukan }\end{array}$ & $\begin{array}{l}\text { Sesuai } \\
\text { Harapan }\end{array}$ & Valid \\
\hline 6 & $\begin{array}{l}\text { Memilih } \\
\text { menu } \\
\text { Laporan }\end{array}$ & $\begin{array}{l}\text { Ketika hasil } \\
\text { penilaian dari } \\
\text { data SAW } \\
\text { sudah ada, } \\
\text { maka hasil } \\
\text { penilaian } \\
\text { dapat di } \\
\text { cetak di } \\
\text { menu } \\
\text { Laporan }\end{array}$ & $\begin{array}{l}\text { Sesuai } \\
\text { Harapan }\end{array}$ & Valid \\
\hline 7 & $\begin{array}{l}\text { Memilih } \\
\text { menu } \\
\text { Keluar }\end{array}$ & $\begin{array}{l}\text { Ketika admin } \\
\text { sudah } \\
\text { selesai } \\
\text { melakukan } \\
\text { aktivitas, } \\
\text { maka admin } \\
\text { dapat keluar } \\
\text { dari halaman } \\
\text { admin yang } \\
\text { akan di } \\
\text { kembalikan } \\
\text { ke halaman } \\
\text { login }\end{array}$ & $\begin{array}{l}\text { Sesuai } \\
\text { Harapan }\end{array}$ & Valid \\
\hline
\end{tabular}

\section{Kesimpulan}

Berdasarkan pembahasan yang telah diuraikan pada penelitian ini, maka dapat disimpulkan sebagai berikut :

1. Dengan aplikasi sistem penunjang keputusan penilaian kinerja auditor ini penilaian kinerja auditor di kantor akuntan publik PEDDY HF.DASUKI dapat dilakukan secara otomatis 
menggunakan metode SAW, sehingga dapat mempermudah manajer dalam melakukan penilaian dengan cepat, tepat dan akurat.

2. Berdasarkan hasil pengujian, aplikasi sistem penunjang keputusan penilaian kinerja auditor ini dapat memberikan solusi bagi manajer di kantor akuntan publik PEDDY HF.DASUKI dalam melakukan penilaian kinerja auditor secara cepat, tepat dan akurat dengan penilaian kinerja dilakukan secara otomatis menggunakan metode SAW.

3. Metode Simple Additive Weighting (SAW) dapat diterapkan untuk mengatur penilaian kinerja dengan kriteria hasil kerja, komunikasi, jobdesk dan kasus.

4. Aplikasi yang dibuat dapat mengetahui karyawan yang layak untuk mendapatkan reward berdasarkan hasil perangkingan menggunakan metode SAW dengan kriteria hasil kerja, komunikasi, jobdesk dan kasus.

5. Untuk pengembangan penelitian dapat dilakukan penambahan metode AHP untuk memaksimalkan fungsi kinerja dari metode SAW. Atau dapat juga mengembangkan penelitian dengan membuat program khusus berbasis desktop yang dapat lebih memaksimalkan fungsi sistem penunjang keputusan yang telah ada.

\section{Referensi}

Anto, A. G., Mustafidah, H., \& Suyadi, A. (2015). Sistem Pendukung Keputusan Penilaian Kinerja Karyawan Menggunakan Metode SAW ( Simple Additive Weighting ) di Universitas Muhammadiyah Purwokerto ( Decision Support System of Human Resources Performance Assessment Using SAW ( Simple Additive Weighting ). JUITA: Jurnal Informatika, III(November), 193200.

https://doi.org/https://10.30595/juita.v3i 4.876

Darmastuti, D. (2013). Implementasi Metode Simple Additive Weighting (SAW) Dalam Sistem Inforamasi Lowongan
Kerja Berbasis Web Untuk Mencari Rekomendasi Pencari Kerja Terbaik. JUSTIN Vol 1 No.2, 114-119

Erfiansyah, E., \& Kurnia, I. (2018). Peranan Auditor Internal Terhadap Kualitas Pelaporan Keuangan. Jurnal IImiah Manajemen, Ekonomi, \& Akuntansi (MEA), 2(2), 144-160. https://doi.org/10.31955/jimea.vol2.iss2 .pp144-160 (20 Mei 2020)

Fauzan, R., Indrasary, Y., \& Muthia, N. (2017). Sistem Pendukung Keputusan Penerimaan Beasiswa Bidik Misi di POLIBAN Dengan Metode SAW Berbasis Web. JOIN Vol 2 No.2, 79-83

Hidayati, T. A., Informasi, S., Informasi, F. T., Luhur, U. B., Utara, P., \& Lama, K. (2018). Sistem Penunjang Keputusan Pemilihan Karyawan Terbaik Menggunakan Metode Analytical Hierarchy Process ( Ahp ) Dan Simple Additive Weighting ( Saw ) Pada Pt . Primasolusi Informatika Nusantara. Jurnal IDEALIS, 1, 444-452. Retrieved from

https://journal.budiluhur.ac.id/index.php /bit/article/view/979 (20 Mei 2020)

Komite Profesi Akuntan Publik. (2020, Desember 18). Luasnya Potensi Jasa Audit bagi Akuntan Publik di Indonesia. Retrieved from kpap.go.id: https://kpap.go.id/2020/12/beritakpap/luasnya-potensi-jasa-audit-bagiakuntan-publik-di-indonesia/

Muhammad, E. (2013). Analisis Profesionalisme, Pengetahuan, Dan Etika Profesi Auditor Terhadap Pertimbangan Tingkat Materialitas Pemeriksaan Laporan Keuangan. Jaffa, 01(1), 1-14. Retrieved from https://journal.trunojoyo.ac.id/jaffa/articl e/view/593 (12 Mei 2020)

Putra, A. S., Aryanti, D. R., \& Hartati, I. (2018). Metode SAW (Simple Additive Weighting) sebagai Sistem Pendukung Keputusan Guru Berprestasi ( Studi Kasus: SMK Global Surya). Prosiding Seminar Nasional Darmajaya, 1(1), 85-97. Retrieved from https://jurnal.darmajaya.ac.id/index.php /PSND/article/view/1233/763 (12 Mei 2020) 
Rachman, R. (2018). Penerapan Metode Simple Additive Weighting ( Saw ) Pada Proses. Jurnal Tekno Insentif, 12(2), 21-27. Retrieved from https://jurnal.Ildikti4.or.id/index.php/jurn altekno/article/view/71/65

Rini, P. P., Dedi, \& Riyanti, N. (2015). Sistem Pendukung Keputusan Pemilihan Dosen Terbaik Berbasis Web Dengan Metode SAW (Simple Additive Weighting) (Studi Kasus: STMIK Global Tangerang). Jurnal Sisfotek Global Vol 5 No.2, 100-108. 